\title{
The Investigation of Physical Design, Executives' Attitude and Policy Towards Service Efficiency Based on Universal Design Principles; A Case Study of Naresuan University Hospital
}

\author{
Charanya PHAHOLTHEP ${ }^{1}$, Thirawut BUNYASAKSERI ${ }^{2}$ \\ and PaweenaPHAHOLTHEP ${ }^{3}$ \\ ${ }^{1}$ Faculty of Architecture, Naresuan University, THAILAND \\ ${ }^{2}$ Faculty of Architecture, Naresuan University, THAILAND \\ ${ }^{3}$ Faculty of Medicine, Naresuan University, THAILAND
}

\begin{abstract}
Public hospitals should be designed to clover as wider inclusivity levels as possible forproviding access for all. Unfortunately, and for a variety of reasons, a quality service is not always provided. When evaluation of the service quality in healthcare organizations is carried out, it is mostly conducted in terms of medical service quality, whilst the physical layout, functionality and facilitating devices are not given as much scrutiny. Post Occupation Evaluation (POE) is notably an efficient process for checking the satisfaction of users after the building has been in-used for a certain period of times. However, hospital is generally a type of building and service that need to support users with a variety of physical capabilities thus, a conventional POE may not cover all requirements of users, so this research has employed the UD concepts as a basis to combined with POE for evaluating service performance of a hospital of the case study, Naresuan University hospital, THAILAND. Even though the POE delivered a good design suggestion that is beneficial to users with a wide range of physical ability but that may not guarantee the new design will be agreed by all stakeholders and implemented through success. As a matter of fact, to success an implementing of a good design does not depend solely on a designer, specifically for this case study, a universal design to a hospital. This research found that to make UD perfectly effects in a hospital (in Thailand context) may require more supportive factors beyond just pointing out problems related to physical conditions of the design and suggest a design solution. As in the context of Thailand, this research identified 4 factors contributing to the success of UD which the designer should be accountable for (1) public understanding of the basic concepts of UD (2) all the related background such as culture, tradition and economic etc. that contributed the attitudes of all stakeholders (of the hospital) towards people with physical impairments (3) the rights, laws, regulations and policies for people with
\end{abstract}

\footnotetext{
${ }^{1}$ Corresponding Author, Faculty of Architecture, Naresuan University, THAILAND,

Email: yummer308@hotmail.com

${ }^{2}$ Corresponding Author, Faculty of Architecture, Naresuan University, THAILAND,

Email: tbunyasakseri@yahoo.com

${ }^{3}$ Corresponding Author, Faculty of Medicine, Naresuan University, THAILAND,

Email:yamroll_med@hotmail.com
} 


\begin{abstract}
disabilities in the context of the country and (4) the participation of all types of users. And in doing so, this research added an extensive evaluation to the general POE to cover as more factors as possible to those involved with the design implementation. Therefore, an extensive evaluation process so called "Comprehensive Post-Occupancy Evaluation C-POE" has been created and employed in this study for offering more comprehensive solution that cover all possibilities cause of problems, the evaluation processes are as follows; (1) evaluating physical features and users' behavior (the experimental access audit), (2) examining administrative policy, HA and UD principles and (3) interviewing attitude of executives about UD.
\end{abstract}

Keywords. Universal Design, Hospital Design, Disabilities, Policy

\title{
1. Introduction
}

A new paradigm for a good public design in the $21^{\text {st }}$ century does not only respond to a single group of users, such as concerning to some people who can pay for it or focusing to special conditioned people with disabilities, but to a wider range of users to be able to use the design together with the same accessibility level. This new design paradigm has been applied to small product through to large scale designs such as the public or residential environment to consider the widest range of users, with the aim to allow for the most accessibility and opportunities for the public to participate in society. This new paradigm of design goes in line with the Universal Design (UD) concept and aims to eliminate social barriers, considering such concept as autonomy, self-organization, ecology, sustainability, adaptation, and potential for continuous improvement (Story, 2001, pp.10.5-10.7). UD essentially based on human rights and equity of access applied to all public built-environments and services.The UD concept holistically gives an importance to the design process concerns on user-centered and user participation design from the beginning of the design development process through to the implementation. (Fuglerud, Halbach, and Tjøstheim, 2015, p. 8) (Steinfeld and Maisel, 2012, p. 15) UD concept consists of seven principles established in 1997 by the Center for Universal Design, North Carolina State University, and has sincecontributed laws, regulations and practices in many countries as a design guideline for architects, product designers and researchers. The seven principles consist of; (1) equitable in use, (2) flexibility in use, (3) simple and intuitive use, (4) perceptible information, (5) tolerance for error, (6) low physical effort and (7) size and space for approach and use (Noppadon Sahachaiseree, 2011). These principles are now considered as a new normal for design and appropriable in various social and cultural contexts (Imrie and Perez, 2016).

Equal access to basic public utilities is a fundamental right of all citizens. Healthcare is a necessityservice which is one of the most important part of social structure. The present-day role and responsibility of healthcare and hospitals is not merely to maintain the quality of medical care but also to procure rights to public health (Right to Health). This includes providing ease of access and satisfaction to all services functions and other built-environments in a hospital for the widest, if not all, the range of physical limitations, genders, ages and so on (Longo, 2012, quoted in Setola, Borgianni, Martinez, Tobari, 2013). In fact, hospital is a type of building that consists of a large assortment of utilitiescreated to fulfill public healthcare requirements and by this reason,the hospitaldesign isalways complicated. (Murphy, 2012). Thus, its essential nature means that good design is crucial. Good architectural designs not only 
gives psychological benefits to patients in terms of visual satisfaction, it also contributes positively to effective medical treatment.For example, well designed interiors and built-environments canprevent patients from falls or other injuries, the use of colors to navigate symbols affects the safety, usability and ease of access to the area for both people with and without disabilities or physical limitations (Verderber and Fine, 2000; Alice, 2008)(Phaholthep, Sawadsri and Skates,2016). In accordance with a Scottish Inclusive expert Rob Imrie, "The physical environment created by humans is an important part, either as a facilitator or as an extension of access to buildings or service areas, especially with people with disabilities." (1995) Similarly, Wolfgang F.E. Preiser stated in Universal Design Handbook that "Hospital is the best place that the UD concept is necessity in the design process." (Preiser and Ostroff, 2001).

This research is contributing to the project named "The Investigation of Physical Design, Executives' Attitude and Policy towards Service Efficiency based on Universal Design Principles; A Case Study of Naresuan University Hospital"which consists of a process of empirical study on structural features and environmental design, mainly focusing on the level of accessibility of people with disabilities regarding the service functions and facilities within the public zone of the hospital.

According to Imrie (2015) it can be determined that the key factors that contribute to the success of a friendly environment for all should consist of (1) an understanding of the basic concepts of UD, (2) attitudes of the executive persons of the organization and the public understanding/expectation are an important factor that determine the physical features in society, such as the collective views of religion and belief toward people with disabilities. As Kroll mentioned in Evidence- based design in Healthcare Facilities(2014), "the influence on public building does not come from architects".To the direct experienced of the researcher (at least in Thailand context) the feature of hospital architecture is decided by policymakers rather than architects and relatively does not base-on user requirements. (3) the design of the environment and facilities, (4) the motivating policy for people with disabilities in the context of each country, and (5) the participation and engagement of all types of users to the building.

\section{Statement of Problem:}

Healthcare Accreditation (HA) is the main criterion used to certify hospital standards in Thailand. HA is a mechanism that encourages the development of healthcare organizations. The HA criteria aims to evaluate standards including levels of safety and security, and the ease of access to services (for all users). HA contributes as an overall aspiration for standardizing a good hospital, however, it does not focus on a concrete evaluation criterion in term of physical design guideline and assessment. For this reason, several hospitals in Thailand always encounter numerous problems caused by inappropriate design even though those hospitals have been certified HA standards. In this case study, the preliminary survey of Naresuan University Hospital (NU Hospital) has identified problems such as the density and congestion of users in several service areas.

Such problems are potentially caused by the inappropriate arrangement of facilities, the number of users that exceed the capacity of the space, or the ineffective wayfinding system. The problems listed above have not only degraded the service functions to users with disabilities or with physical impairments but also other general patients. In the designer's point of view, the preliminary survey shows that UD design principles may be effective in providing straightforward solutions to these problems. 
However, the implementation of UD is not as easy as the first considered as it challenges many of the prevailing conditions of the as-built functions of NU Hospital.

This research begins by observing activities and phenomena in the in-used functions in the as-built condition of NU Hospital service areas. The operation employs qualitative methods based on evidence-based approach (EBA) and creates integrated processes which consist of survey and observations, experimental access-audits, comparative studies and, a post occupation evaluation (POE) for understanding the problems and for contributing new knowledge that can be applied to future cases with similar conditions. The assessment methods are divided into 3 levels, firstly for identifying general problems, the assessment operated by walk through observation by a researcher and five UD experts (Preiser et al., 1988). Secondly, for confirming problems, the investigation employs UD criteria and operates by an experimental access audit within a real and specific space with a usual usage behavior). The subjects are a person with a real physical limitation and designers simulated themselves into an elderly person or a person with hearing, vision, mobility impairment. Lastly, for diagnostic investigating, which is a process that includes an in-depth analysis of the problems encountered in the assessment one and two. The operation relies on a comparative study between the best practice of international standard of hospital design and an actual space, and physical environment within NU Hospital, together with the recorded number of users within the investigated area. The three assessment methods employ UD framework to identify specific problems that reduce services and functional efficiency at NU Hospital for those general users and those with low physical abilities (Phaholthep, Sawadsri and Skates, 2016, pp. 517-526).

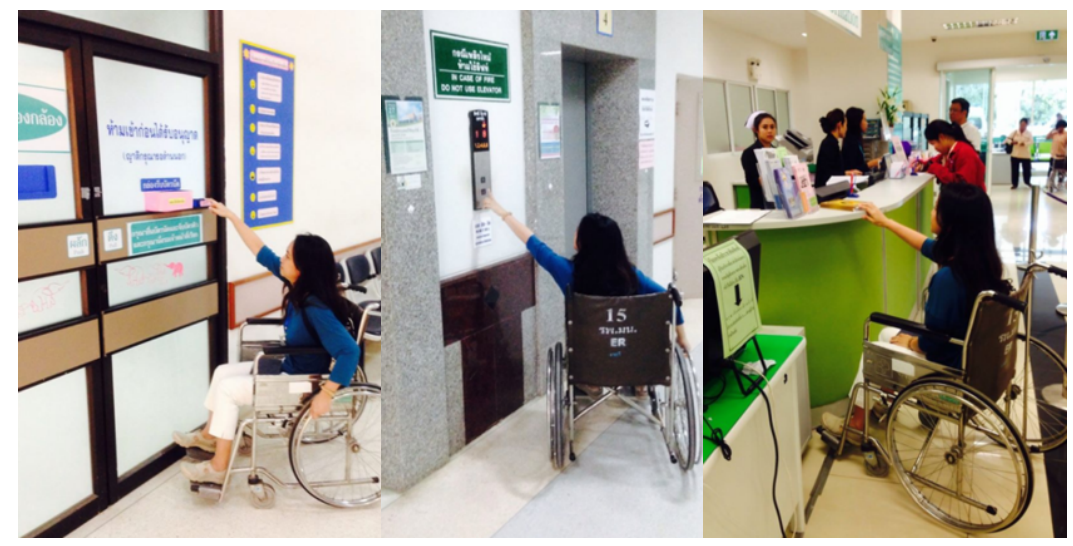

Figure 1: Experimental Access Audit by UD expert simulated as a wheelchair user to audit the service functions of NU hospital

In fact, the post occupation evaluation (POE) allocates problems that arise from physical design and facilities after the building has been occupied for a certain time, this evaluation may also evaluate a given spatial size of an as-built building in relation to an actual number of users. This research has specifically employed UD criteria focused on the environmental behaviours of users with physical limitations to increase the accuracy of the result and coherent with the case study. Although the evaluation of physical design operated in this study may accurately identify problems of the design and give suggestions for a future improvement. However, the design suggestions made 
by a designer is only a part of the decision for physical improvement and somehow, it may not be considered as an urgent issue compared to other investments. In an actual situation, there are still many other concerns, such as a hospital's policy, a budget allowance, and the attitudes and agreements required by building-users or executives who have the power to make decisions. This research found that the real obstacle in implementing UD to the hospital in this case may not be relied to the knowledge of design, but also about convincing all the mentioned stakeholders to understand the importance, benefits, and worth of implementing UD in the hospital. For this reason, this research has included this issue as an important part of evaluation and created a comprehensive method to use along with general POE. The method called "A Comprehensive Post Occupancy Evaluation - CPOE" is a method created in this research to increase the effectiveness of the evaluation, the accuracy of the result and sustainability of the solution. The distinction of C-POE is the extensive investigations on other important contextual factors that is not directly about designing practice but after all, have a great effect to physical design of NU Hospital. And this article will focus more on the studies and investigation of the thought and attitude of executives about (investing budget to) implementing equal access or UD to hospital service areas.

\section{Objective}

- To study the consistence/coherencebetween Universal design concepts and the implementation in the hospital.

- To study the attitudes of executive and the users' requirements toward the concept of Universal Design and implementation within Naresuan University hospital.

- To suggest factor the possibility of Universal Design application towards increasing service efficacy in hospitals.

\section{Methods}

This is a qualitative based research with an emphasis on the pursuit of knowledge by considering the phenomena within an actual context, and to find the relation of the phenomena with the as-built environment. This research employs mixed methods, including a comparitive study, a content analysis, and an interpretation of the results to answer the research objectives. The details of the methods are as followed;

- Study the relevant information, which consists of 2 majors, (1) Hospital Accreditation (HA) as it is a benchmark used in quality control of hospitals in Thailand and, (2) The seven principles of Universal Design (UD7).

- Compare the information between HA and UD to identify the criterion validations and contradictions. The advantage of this method is to understand the standardization of the HA that reflects the physical design of hospitals regarding the UD concepts.

- Content analysis to find the needs of stakeholders who are involved in using the hospital's facilities and services. This involved in-depth interviews with stakeholders about their satisfactions and the problems they experienced that affect the efficiency of hospital's services, their perspectives on people with 
disabilities, and their suggestions on how to improve the physical design of the hospital to increase service efficiency in a manner that is appropriate to everyone- especially to those with physical limitations. The group of stakeholders are categorized as service providers and users, including 8 hospital staffs who perform their duties in the service areas of the outpatient departments and 12 patients and their relatives. The duration of these interviews were approximately 45 minutes per person.

This method also includes the interview of NU hospital executives, the content analysis in this method was conducted to examine the hospital's policy and the attitudes of executives that encourage the use of UD 7 principles and people with disabilities and the elderly. This process involved in-depth interviews about the strategies to increase efficiency based on UD principles. The interviewees were 4executives who have decision-making power to establish policies and determine the direction of the hospital's physical design. The duration of the interviews were approximately one to two hours per person. The purpose of this interview is to know the hospital's policy and the personal opinions of the executives, and whether these align with the UD concept.

The questions in the interviews of both groups (general building users, patient staff, patients' relatives and hospital administrators) are based on the results of POE done earlier in this project. So, the interviewees in both groups have known or in some cases, have had direct experiences with the problems. Therefore, the answers from the interviews closely represent the real needs of stakeholders for this hospital context.

- Conclude the results from the Comprehensive post occupancy evaluation process; CPOE process and propose a design using UD concepts that adjust the existing environment and functions of the hospital and improves the efficiency of services.

\section{Results}

\subsection{Summary of the comparison and alignment between the concepts of Hospital Accreditation (HA) and Universal Design (UD)}

To identify and analyze the alignment between the hospital policy that may possibly contribute UD concept toincreases the service efficiency of the hospital. This process employs a comparative study between the HA guideline that determines the development direction of the (NU) hospital of the case study and the 7 principles of UD (UD7); (1) equitable use, (2) flexibility in use, (3) simple and intuitive use, (4) perceptible information, (5) tolerance for error, (6) low Physical effort, and (7) size and space for approach and use. Therefore, the study found that the HA criteria which NU HNU Hospital used as the development guideline did align with UD7 in 3 units of HA as follows.

- Unit 1: The HA is a criterion standard of hospital organization and management which the contents is consistent with the 7 principles of UD (UD7) as follows: (1) equal and timely access to healthcare services without any discrimination, which is a fundamental right of all people (including the elderly and people with disabilities) according to the constitution. (2) ease of 
access to the location and prompt adjustment to suit each client, 3. safety in areas of use and service. These three criterions of HA are aligned with the UD7-1, UD7-2, UD7-5 and UD7-7.

- Unit 2: HA standardizes a physical environmental and maintains safety for patients and staff by dividing utility spaces of a building to facilitate patients with safety, comfort and privacy. The HA unit 2 standard is considerably in line with the UD7-1 Equitable use which includes the privacy of users, UD7-5 Tolerance for error and UD7-6 Low Physical effort as well as convenient in use.

- Unit 3: HA is concerned with the ease of access for patients to a service which encourages a hospital to reduce service accessibility barriers in terms of physical design, language, culture and other obstacles. The necessary information and process of services must be clearly displayed and easy to understand regardless of the level of patients' education or physical abilities. The HA unit 2 standard is considerably in line with the UD7-2 Flexibility in use, UD7-3 Simple and intuitive use, UD7-4, Perceptible information, UD7-5 Tolerance for error which includes reduction of obstacles in service areas, UD7-6 Low Physical effort which includes easy access, and UD7-7 Size and space for approach and use (to all service areas).

In summary, the HA standard NU HNU Hospital used for quality control is likely consistent with UD7. Although, this study found that the HA criteria has rather given an aspiration for outlining a development plan without a concrete indicator, especially in terms of physical design. However, the alignment between the concept of HA and UD resulted in this part of study still considered important as it provided information which shows the possibilities to apply UD concept to increase the efficiency of services at NU Hospital.

4.2 Summary of the Attitudes of the Hospital Executives Towards the UD Concept and the Policy of NU Hospital

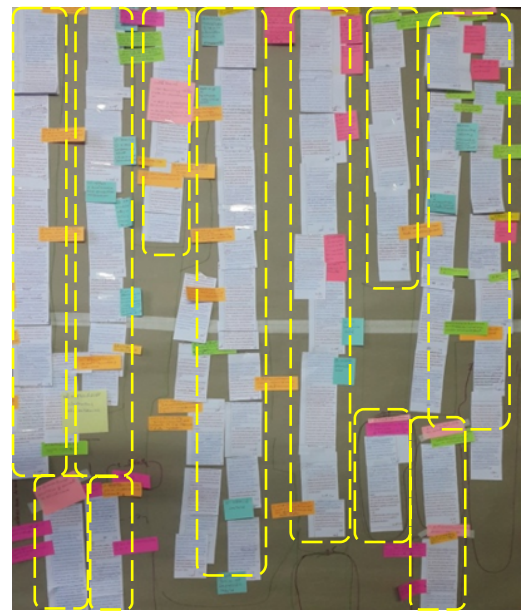

Figure 2:The image illustrates the Content Analysis and Interpretation process to categorize the executives' attitude towards the UD concept 
A summary from the in-depth interviews of four hospital administrative committees who are involved in /policy/decision making, and their opinions on whether to use or not to use the UD concept to increase the efficiency of NU Hospital services. This group consist of (1) the director of NU - Hospital, (2) the deputy director for planning and management, (3) the deputy director for environment management, and (4) the head of department of orthopedic surgery. The questions in these interviews are based on real problems identified from POE in the previous study of this project that affect the efficiency of NU Hospital services. The interviews found that all executives have been being aware of these problems. There are four questions in these interviews that asks the executive's; (1) opinion towards an existing (general) problems that affects the efficiency of the hospital, and their opinion on the most effective policy to resolve these problems, especially in response to people with disabilities and the elderly, (2) opinion about the most effective strategy to deal with the high density of patients those congest and affect the service areas for the general public, but especially for people with disabilities and the elderly, (3) opinion about the existing way-finding system in the hospital, such as a floor plan layout, service locations and service flow, and signages and communication systems, and whether these meet the needs of the general public, and especially people with disabilities and the elderly, (4) opinion about the list of facility improvement planning based on the regulation by the Thai Ministry of Interior 2005, and to give their reason as to why one facility has a decision to improve before others. The answers to the four questions from all four administrative committees have been interpreted by the content analysis method to find linkages and alignments with the UD concept or UD7, which would potentially meet the needs of people with disabilities and the elderly.

The analysis of the attitudes of the four administration committees towards the UD concept, the answers from all interviewees clearly reflect the mindset of empathy according to Mike Oliver 's The Social Model of Disability (1996). The content analyzing process employs Verbatim analysis method in corresponding with the Text mining method to turn the data into a statistical summation with a clear quantifiable picture of sentiment on the given topic. The result from the content analyses classifies the attitudes about UD concept and hospital service improvement of the four administration committees into two directions as supportive and non-supportive attitudes towards the implementation of UD to the hospital services. The details and examples are as follows:

\section{Direction 1: Supportive attitudes towards applying the UD concept to NU Hospital.}

- If hospital have enough funding, UD should be worth investment because it can be of benefit to most people.

- UD has the potential to make the hospital environment free of risks and hazards to most people.

- The concept of UD is consistent with many HA criterions, which NU Hospital compulsorily uses for ensuring high standards of quality, such as safety concerns.

- UD should be a foundation of hospital design planning and process because all patients are likely to have physical impairment to some extent and may require the use of wheelchairs. Therefore, UD should be a benefit for both the present and future. 
- UD is a concept that creates sustainability in hospital services efficiency and is considered a long-term investment that provides long lasting results without additional costs, especially if implemented at the beginning of the design process.

- UD is a concept that creates a more convenient lifestyle and leads to happiness in society. UD is also a concept that increases public consciousness for others in society.

- UD is a flexible concept that can be implemented to suit various context. NU Hospital uses physical facilities combined with volunteers to assist patients in various situations. This strategy is consistent with the UD strategy called Reasonable Accommodation (RA) or Assistive Technology (AT).

\section{Direction 2: Non-Supportive attitudes towards applying the UD concept to NU Hospital.}

- Social and cultural context in Thailand and user's behaviors do not align with the UD concept of independent living, which includes younger people caring for the elderly. This is most preferable (for the elderly) in Thailand as it represents gratitude for parents or older people.

- There are many forms and levels of illnesses which results in physically weak patients at NU Hospitals. To implement UD and allow patients to move independently may not be safe and may increase the difficulty to access service. UD would be more effective at other suitable places where users have greater physical mobility, such as airports or bus/train station.

- The NU Hospital building may be limited to adaptation. It is highly complex and inconvenient to reconstruct a new physical environment to comply with UD, or to implement UD devices to the as-built building because all wards in NU Hospital must be prompt with their daily medical services and duties.

- Investment budgets will be increased as the building is already in-used and it may not be worth the investment due to the low number of people who really require it. Other assistive methods may work better.

- Number of users with disabilities or people who really require UD devices are small compared to able-bodied users, therefore, it is not worth the investment. Other assistive methods may work better.

In conclusion, the analysis of the attitudes of the administration committees towards the UD concepts and the implementation of UD devices to NU Hospital found that the majority of attitudes classified as supportive is due to their view of the future benefits, such as reducing the risk of injuries, the flexibility in application to spatial context, and the sustainability improvements of the building as well as society. Ideally, the implementation of UD should be planned at the beginning of the design process to limit its effect on the allowance budget.

On the other hand, it is found that the non-supportive attitudes towards implementing UD devices to NU Hospital is due to concerns based on the physical limitation of patients, who are generally unable to look after themselves or are under medical conditions. The hospital as-built building is also a further concern, as it may be limited to adaptation or improvement based on UD concepts. Moreover, as the hospital is already built and in-used, the construction of UD devices will affect the daily 
medical services and incur additional costs as well. Finally, the limited number of users with disabilities is also of concern, along with the social and cultural context in Thailand which affect users' preferences and behaviors, including their willingness to care for the elderly. These factors result in non-supportive attitudes towards the implementation of UD concept to NU Hospital.

\subsection{Result Summary of NU Hospital Policy Analysis from the Comparative Study with UD7 and the Experimental Access Audits}

From the interview with the 4 executives of the hospital, this research approaches to examine the hospital policy in comparison to the UD 7. The interview form is using the same question as the study of executives' attitudes in section 4.2. In order to identify the real problems and solutions that meet the needs of people with disabilities and the elderly, the researchers used these interview results to compare side-by-side with the UD7 and the problems found in the Experimental access audit.

The studiescan be summarized that the hospital policy is in line with the UD7, which can be classified into 5 groups and can explain the details of each group in comparison with HA and UD as follows.

1. The policy of patient accessing the service area: the hospital environment must be safe, no risk of using any function or space, easy to access, reducing exertion in functional and spatial usage for all. For example, providing navigation system for visually impairment from the bus stop and drop-off point to the building, an audio queue calling, easy understanding information for the elderly and illegible people etc.

2 . Policy of service area management: The service area management must cover as many types of users across physical abilities, visual access of each department must be clear and easy to understand, spatial sizing must be appropriate for the activity, the number of users and also for the wheelchair users, easy access/reduce exertion and risk of access for user with disabilities, the elderly and people with weak conditions.

3. Policy of the service flow; it must be continuity between one department to others and follow the sequent order of medical service, each department signage must be easily perceived without confusion, pathway sizing must be suitable for the flow of users without overcrowding or people queuing across the circulation pathway.

4. Policy of communicative and informative systems: All the systems must be easily and instinctively to understand such as the signage must be communicated by using symbol rather than language or in unavoidable case, using spoken language, displayed at easy visible spot for all users (including view from the wheelchair vision level) with appropriate size and color. In case of visually impaired people, providing guidance symbols such as tactile paving or audio guidance or assistance staff to indicate directions.

5. Policy of safety: The hospital environment must be zero risk and hazard such as non-slipping floor paving, warning paving for blind, handlebars for wheelchair ramp etc. For circulation pathway outside the hospital building, all pathways and pedestrians must be clearly separated or barriered from traffic surface to prevent accident for the visually impaired, children and all other users. This policy is directly related to the UD7-1 and UD7-5, equality and safety for all. In addition, there is also another policy that is not related the UD7 but has been managed to improve service efficiency for users. It is the use of volunteer helpers standing by many points in the hospital for readily giving assistance to any patient in case of needed. 


\subsection{Summary of Factor Analysis that Affects the Feasibility of Applying UD to Increase} Service Efficiencyof NU Hospital

According to the factor analysis of the NUHospital policy and the management attitude of administration committees towards the benefit of UD concept for increasing the service efficiency of the hospital, to meet the needs of people with disabilities, the elderly and to all general users. The identified factors can be summarized as follows:

1. The consistency of the rules of HA that standardize a hospital in Thailand, the NU hospital policy and the UD concept. The law must be written with a real concern for all users, perhaps using the UD concept and should have clear penalties and enforcement strategies.

2. Knowledge and understanding of UD and awareness of human rights equity and respect for the rights of others.

3. Allows everyone involved with the hospital, such as administration committees, medical staffs, people with ability/disabilities and designers etc. to have a participation in determining their own needs from the outset of the design process.

4. Changes in social structure such as aging/aged society that affect economic tendency.

5. The social attitude towards people with disabilities, especially executives or other people in charge who make policy and hold decision power to direct budget and investment.

\section{Discussion}

This article is a part of the full research which focuses on examining two factors; the policy of NU hospital and the attitude of executives towards the possibility to implement UD principles to increase the efficiency of services. In fact, NU Hospital is already in-used so the evaluation of the existed functions should be done prior to any decision to change or improve its physical environment. This research comprehends the concept of UD and evaluates the existed functions by POE approach(Phaholthep,2018). This comprehensive evaluation firstly focuses on a physical inspection of NUHospital then proceeds to identify/examine the initial cause of problems that contributes to the reduction of service quality, especially to people with disabilities and the elderly. In order to do so, this research divides the purpose of evaluations into 3 aspects: (1) evaluation of physical design and functions, (2) evaluation of the hospital policy and (3) evaluation of executives' attitude. Finally, the results from the evaluations will be determined and propose a solution that comprehensively and sustainably solve the initial causes of problems.

Aspect 1: Physical examination shows that the cause of physical problems affecting the service performance based on UD concept consists of improper space management, inappropriate area management per number of people, placement of activities on other living areas, not enough space and size, navigation system is incomplete, lack of appropriate facilities for people with physical limitations, lack of voices and input from those stakeholders involved in the use of hospitals in design planning process; such as staffs working in the area disabled people. Facilities for providing services from the outset (from interviews and from experimental access 
audits,simulating people with physical limitations to try to use the space) etc. (Phaholthep, 2018).

Aspect 2: The comparative study between UD concept and HA standard that NU hospital used as fundamental to make its policy, the result of this study found that the overall hospital policy is consistent with UD7 which serves the needs of people with hearing, visual, and mobility impairments as well as the elderly.

Aspect 3: The attitude of executives acquired from the intensive interviews demonstrated that most of executives' attitude do support and encourage the use of UD principles to improve service efficiency in NU hospital. According to the conceptual framework of this research, the physical design, the hospital policy and the executives' attitude are all important related factors that needs to be consistent to contribute to a friendly environment for all.

Although NU Hospital executives apparently agree that UD is a likely solution for improving service efficiency for all, this research also found that there are other factors that prevent the implementation of UD; (1) UD concepts are not concretely specified in hospitaldesigncriteria (HA) as well as in the physical design planning of NU Hospital (2) UD concepts and UD 7 principles is not concretely specified in the hospital design standard. For example, there isno specification for standard sizing or measurement guideline for waiting areas, sitting space or circulation pathway that consider the needs of all people across physical abilities, including those requiring wheelchairs. In responding to this issue, this research has interviewed the executives of NU hospital who have authority to make decisions and found two major reasons of unsupportive attitudes towards applying UD to the hospital. First, the worth of investment because the number of users with disabilities is significantly less when compared to general users. Second, the cultural, social perspective or collective mentality about people with disabilities in Thailand, as these types of people are frequently considered as a weak, pitiful and as pathetic people who should be specially assisted by merciful caregivers, rather than being supported to become more independent-living with more appropriated built-environments based on UD.

Other difficulties in implementing UD application to NU hospital are the conventional mindset of equity, the different types and extent of physical limitation and medical conditions of patients, and the investment costs to renovate the existing building with UD principles. Although the case of equity is a fundamental aspect of UD, the inspection operation of this research (the experimental access audit) found that the people with disabilities who volunteered to perform an access audit in a real situation were rather satisfied and willing to be assisted by a caregiver or relatives, rather than to be able to access services by themselves. Another issue identified in this research is the physical limitations of a patients under medical conditions or treatments. During illness, some patients with major conditions may truly require a caregiver, while many other patients with minor conditions and under minimal treatment should be able to access services by themselves. However, in real situations, it is not easy for hospital staffs to determine which patients are those who truly require caregivers. For this reason, the hospital dismissed the use of UD concept to improve the hospital service area, instead, prefers to employ volunteers who are able to provide care and assistance for patients with a reasonable accommodation (RA). Finally, the possibility of UD based improvement comes down to the cost of investment and the inconvenience that will cause to the hospital daily services as it is already in-used. As a matter of fact, the renovation of any service area will affect the daily medical services space and may not be sustainable to solve the problems according to the problem 
analyses of this research (C-POE). The solution for this problem may rely on the reorganization of the service space and the additional assistive technologies/devices to increase the convenience of services to all users, such as the online appointment application, the audio/digital screen calling system, or the queue barrier.

\subsection{Possibility of physical improvement in NU hospital to benefit all users.}

The in-depth studies and analyses identified that the functions from outside into NU hospital building should have some changes with UD application for all users can access the building safely and conveniently. Because there is no hospital staff in those areas to assist users if needed, the list of improvements according to this study and to the opinions of UD design experts and the hospital staffs are as follows; wheelchair ramps, organization of pathways must be improved with appropriate size and separated between walkway and vehicle, needed guiding blocks for visual impairment, disability car parks at the nearest location to the building entrance are also required improvement. At the entrance inside the building, it should have improved physical functions with UD application as well, or alternatively provide some staffs/volunteers on standby in the area who can assist following the concept of the Reasonable Accommodation (RA) and Independence Living (IL). This proposed improvement is in line with the opinions of UD experts, executives and operation staffs.

The Independence Living (IL) and Reasonable Accommodation (RA) are the fundamental rights forpeople with disabilities and the elderly, which the hospital should (must) provide regardless of the number of users. And UD facilitations should (must) also be provided as a choice to increase service efficiency or ease of access, whether the users decide to access the function independently by UD facilities or willing to be assisted by hospital staffs/their relatives. Additionally, the hospital may provide other assistive technologies (AT) as an alternative choice to assist patients access services.

To this case study, overcrowding at many service areas is also another major problem that needs to be considered. The high density of patients and patients' relatives exceed the space's capacity during peak periods, this problem maycause by inappropriate circulation, wayfinding and service organization systems, which this study identified as one of the initial causes that reduce the quality to all other service functions at NU Hospital. Therefore, the high-density managements, spatial reorganization or additional accessing and navigating technologies should be highly considered and proposed to improve the situation.

Design for all or UD is not just about a physical design, but it is also a process to create equity for all people in society that reflect in public environments and services that benefit all. According to the case study of NU Hospital, to encourage UD to increase the service efficiency, the following factors should be considered; (1)Government should include UD principles in the laws and regulations of public buildings, with effective strategies to enforce practices and penalties for noncompliance. Specifically, the government should develop a standard for hospital design with a concrete measurement guideline for determining physical environment that employs UD7 as a basis to suit all users across physical abilities. (2)UD should be considered from the outset of the design process to prevent and reduce any additional costs or difficulties and inconveniences that may occur instead of the additional costs that would be required to renovate an in-used building. (3) All stakeholders involved with the hospital, including the designer, executives, staffs, general users and users 
across all levels of physical impairments should have an opportunity to participate in the design process and be given equal importance. Investing a budget for UD should not be judged only in terms of economic capital, but also human and social capital should be equally considered because the benefits will be in the invaluable improvements made to the quality of life and welfare of all people in society.

This research was done to find the possibility to apply the UD concept to the hospital. The core of this research is the process of applying UD concepts to improve hospital service efficiency.

To summarize, this research firstly aimed to find a real possibility to increase service efficiency according to the seven principles of UD. This research began the process by employing POE method to evaluate the existing physical conditions of NU Hospital. However, this researchlater found that to create/implement a successful and effective public environment and service for all is not solely dependent on a designer/architect, or the quality of design practices alone. There are many other important factors such as mutual understanding and the agreement between executive decision/policy makers, the participation of stakeholders, and the availability of funding. For this reason, this research presumes that the identified problems acquired from POE can only indicate the problems related to physical design but may not be comprehensive and effectively solved the initial cause of problems. In order to offer a deeper explanation about the cause and the solution of the existing problems related to services at NU Hospital, this research created a further investigation called "Comprehensive - Post Occupation Evaluation (C-POE)". C-POE covers morerelated factors and parties that involved the NU Hospital design process, such as law and regulations that standardizes the hospital design in the country, the attitudes of hospital administration committees, staffs and all types of user across physical abilities. The researcher expected that the result of research will directly give a more comprehensive solution to NU hospital, and at the same time extend on the effectiveness of the conventional POE to be able to indicate problems with more sustainability.

\section{References}

[1] Fuglerud, K. S., Halbach, T. and Tjøstheim, I., Cost-benefit analysis of universal design: Literature review and suggestions for future wor, (C) Copyright NorskRegnesentral, (2015).

[2] Holmes-Siedle, J., Barrier-free Design A manual for building designers and managers, (1996), pp 9-13.

[3] Department of Empowerment of Persons with Disabilities, Ministry of Social Development and Human Security (MSDHS), Thailand. Sample Models of Facility Design for A Person withDisability and All Ages, Second Edition.

[4] Imrie, R., The body, disability and Le Corbusier's conception of the radiant environment, (1999).

[5] Imrie, R., Socializing design and equitable living: Towards an assessment of the relevance of universal design, Lecture given on 20 October 2015 at Griffith University Queensland College of Art, Australia, (2015).

[6] ImrieR. and Hall P., Inclusive Design Designing and developing accessible environments,(2001), pp. 936, Spon Press. Taylor and Francis Group.

[7] Imrie, R. and Perez, B., Inclusive Designed Environment and Research, The Forum 2016. Lecture given on 15 January 2016 at Novotel Bangkok Suvarnabhumi Airport Hotel, THAILAND,(2016).

[8] Kitchin, R.,"Out of place', 'knowing one's place': space, power and the exclusion of disabled people', Disability \& society, 13(3), (1998), pp. 343 - 356.

[9] Kroll, K., Evidence- based design in Healthcare Facilities, Retrieved September 8, 2014, from http://www.facilitiesnet.com/healthcarefacilities/article/Better-Health-From-Better-Design-FacilitiesManagement-Health-Care-Facilities-Feature--2425,URI: http://shura.shu.ac.uk/id/eprint/492,(2005).

[10] Longo, E., Le relazionigiuridichenelsistemadeidirittisociali, Profiliteoricieprassicostituzionali. Retrieved from http://works.bepress.com/erik_longo/1/,(2012). 
[11] Murphy, P., Way-finding Planning for Healthcare Facilities, GNUgroup. Retrieved from http://www.gnugroup.com/thought-leadership/healthcarewayfinding/,(2012, February).

[12] Oliver, M., The politics of disablement. London: Macmillan Press,(1990).

[13] Phaholthep, C., Factors to Apply Universal Design Principles in Increasing Service Efficacy in Hospitals: A Case Study of Naresuan University Hospital,)Thesis of Faculty of Architecture Kingmongkut's Institute of Technology Ladkrabang), (2017).

[14] Phaholthep, C., Sawadsri, A., and Skates, H., An Evaluation of Public Space AccessibilityUsing Universal Design Principles at Naresuan University Hospital, In Langdon et al. (Eds.), Designing Around People.CWUAAT 2016.Springer., DOI 10.1007/978-3-319-29498-8_24, (2016), pp.231-236.

[15] Phaholthep, C., Sawadsri, A., and Skates, H., A Comprehensive POE Process for Investigating Service Efficiency based on Universal Design Principles: a case study of public zones in Naresuan University Hospital.Zuo, J., Daniel, L., and Soebarto, V. (Eds.), Fifty years later: Revisiting the role of architectural science in design and practice: 50th International Conference of the Architectural Science Association 2016, The Architectural Science Association and The University of Adelaide, (2016), pp.517-526.

[16] Preiser, W. F. E., \&Ostroff, E. (Eds.), Universal design handbook, McGraw-Hill, New York, NY, USA, (2001).

[17] Preiser, W. F. E., Rabinowitz, H. Z., \& White, E. T., Post-Occupancy Evaluation, New York, USA: Van Nostrand Reinhold, (1988).

[18] Sahachaiseri, N., Universal design, Teaching documentary, King Mongkuk's Institute of Technology Ladkrabang, Thailand, (2011).

[19] Setola, N., Borgianni,S .,Martinez ,M ., andTobari ,E ., The role of spatial layout of hospital public spaces in informal patient-medical staff interface, In Proceedings of the $9^{\text {th }}$ international space syntax symposium, Sejong University, Seoul, South Korea, (2013).

[20] Steinfeld, E. and Maisel, J.L., Universal Design: creating inclusive environments, NewJersey: John Wiley \& Sons, Inc, (2012).

[21] Story, M.F., Principles of Universal Design, In Preiser, W.F.E. and Ostroff, E. (Eds.),Universal Design Handbook, McGraw-Hill, USA. (2001), pp.10.5-10.7.

[22] The Center for Universal Design,The Principles of Universal Design, Version 2.0. Raleigh,NC: North Carolina State University, (1997).

[23] Verderber S, and Fine D., Healthcare architecture in an era of radical transformation, New Haven and London: Yale University Press,(2000). 